\title{
A Semiose da Diversidade Materializada na Comunicação Turística do Carnaval de Recife - 2019
}

\author{
La semiosis de la diversidad expresada en la comunicación turística del \\ Carnaval de Recife - 2019
}
The semiosis of diversity expressed into tourism communication of Recife' Carnival - 2019

Ma. Priscila Gayer ${ }^{1}$

\begin{abstract}
Resumo
O presente artigo busca compreender como e quais sentidos são acionados na semiose da diversidade, assim como esse símbolo se materializa na comunicação turística do Carnaval de Recife (2019). Para isso, são apresentadas as premissas teóricas sobre a semiótica e uma discussão teórica sobre a diversidade. A análise permite compreender que, ainda que os signos sejam compostos com base em sujeitos locais e seus elementos culturais, o conjunto que retrata o símbolo da diversidade traz no seu cerne a ideia de variedade, mais do que a problematização ou qualificação das particularidades presentes nas diferenças. Assim, a diversidade é tratada a partir de um discurso universalizador, permitindo inferir que símbolo da diversidade pode ser compreendido enquanto universal, na medida em que poderia ser replicado em qualquer outra realidade sem modificar seu sentido.
\end{abstract}

Palavras-Chave: semiose; diversidade; comunicação turística; carnaval de Recife.

\section{Resumen}

Este artículo busca comprender cómo y qué significados se desencadenan en la semiosis de la diversidad, así como este símbolo se materializa en la comunicación turística del Carnaval de Recife (2019). Para esto, se presentan las premisas teóricas sobre la semiótica y la discusión teórica sobre la diversidad. El análisis nos permite comprender que, aunque los signos están compuestos por sujetos locales y sus elementos culturales, el conjunto que representa el símbolo de la diversidad tiene en su núcleo la idea de la variedad, en lugar de la problematización o calificación de las particularidades presentes en el diferencias. Así, la diversidad se trata desde un discurso universalizador, este símbolo puede entenderse como universal, ya que podría replicarse en cualquier otra realidad sin cambiar su significado.

Palabras clave: semiosis; diversidad; comunicación turística Recife Carnaval.

\begin{abstract}
This paper aims at understanding which meanings compose the semiosis of diversity and how it is materialized into the tourist communication of Recife's Carnival (2019). So, the concepts regarding to semiotics and to diversity are presented. The analises allows to comprehend that, although the sign are composed by local subjects and its cultural elements, the semantic background portrait the diversity as variety and do not attempt to problematize or to qualify the particularities of the differences that characterizes the diversity. In this manner, the diversity is brought to light through a universal speech and so it can be set as universal, since it could be applied to any other place without changing the core meaning.
\end{abstract}

Keywords: semiosis; diversity; tourist communication; Recife Carnival.

\footnotetext{
${ }^{1}$ Doutoranda em Comunicação (UFRGS); Universidade Federal do Rio Grande; Rio Grande, Rio Grande do Sul, Brasil; prittyla@gmail.com
} 


\section{Introdução}

A presente pesquisa tem como lócus de investigação a comunicação turística, entendendo que a esfera comunicacional é constitutiva do fenômeno do turismo. Pensar na possibilidade de desenvolvimento do turismo em uma localidade pressupõe conceber, desde o planejamento turístico, as imagens e os imaginários que irão compor as representações e signos a serem comunicados acerca desse destino turístico (GASTAL, 2005). Isso porque o destino passa a existir socialmente e a ser desejado a partir de processos comunicacionais e de sentidos negociados entre produtores e consumidores do turismo (BALDISSERA, 2010). Reforçando esse pensamento, Lipovetsky (2011) defende o princípio de que "o que não dá imagem e não é midiatizado não existe, e isso até nas ilhas desertas, nos paraísos solitários, que as agências de viagem oferecem" (LIPOVETSKY, 2011, p.83).

Partindo do âmbito da difusão e da visibilidade do turismo através da comunicação, ao analisar documentos veiculados pela comunicação turística entre 1930-1955, com intuito de compreender as transformações da imagem turística do Uruguai, Cunha et Al. (2012) sinalizam a importância da atuação dos diferentes meios de comunicação utilizados. No que tange a capacidade da comunicação em produzir e espelhar os valores socioculturais que envolvem o fazer turismo e as práticas socioculturais atreladas ao fenômeno, esses pesquisadores justificam a análise dos materiais comunicacionais tendo em vista que neles se pode compreender o desenvolvimento dos destinos diante das práticas sociais, das formas de consumo e de diferenciação social inerentes ao período analisado. Portanto, os meios de comunicação são atravessados pela dimensão social ao passo em que a conformam.

Logo, a comunicação turística ocupa uma dimensão ampla dentro da produção do turismo. Ou seja, vai além da negociação sobre o que é atrativo e da capacidade de torná-los visíveis. Para abarcar os aspectos inerentes à comunicação turística, Baldissera (2010a) desenvolveu esse conceito englobando todas as formas de comunicação que circunscrevem a produção do turismo e a experiência turística, envolvendo a promoção, persuasão, informação, capacitação e formação, sensibilização, engajamento, etc. Dessa maneira, as formas de comunicação no turismo não se restringem às ações midiatizadas, mas abarcam igualmente as relações intersubjetivas presenciais.

comunicação turística é toda comunicação que se realiza no âmbito das relações de turismo, em seus diferentes processos, suportes e contextos, ou seja, compreende a comunicação que, de alguma forma e em algum nível - formal e/ou informalmente, atualiza/materializa sentidos relativos às ideias e às práticas de turismo. (BALDISSERA, 2010a, p.68). 
Diante desse breve contexto, a primeira premissa parte da centralidade que a comunicação ocupa na formação do fenômeno do turismo, seja pela visibilidade proporcionada aos destinos, atrativos e serviços turísticos, ou pela condição de produtora dos valores que envolvem as práticas turísticas, ou ainda enquanto forma de interlocução que permeia a experiência turística.

O segundo argumento advém dos usos dos eventos culturais na elaboração da imagem dos destinos. Essa prática ocorre em decorrência da possibilidade de expressar a aura simbólica do local através das festividades. Dessa forma, as festas populares tem sido incorporadas ao conjunto de atrativos turísticos das cidades e, por vezes, tornaram-se signos que representam essas localidades. Como exemplo: os carnavais de Salvador, Rio de Janeiro e Recife; as festas de São João de Caruaru (PE) e Campina Grande (PB); O Festival de Parintins (AM); a Festa da Uva em Caxias do Sul (RS). Essas manifestações culturais são utilizadas nas estratégias comunicacionais voltadas para a construção da imagem de destinos turísticos.

Articulando comunicação turística e festas populares, a pesquisa em questão tem como objetivo geral compreender como se materializa, na comunicação turística do Carnaval de Recife, o jogo de signos (semiose) associados na representação do símbolo da diversidade. Para isso, foram traçados os seguintes objetivos específicos:

- Identificar, na constituição do símbolo da diversidade, os signos presentes de acordo com os níveis de apreensão dos fenômenos (primeiridade, secundidade e terceridade);

- Compreender como esses signos se articulam na formação do símbolo da diversidade;

- Analisar o caráter do símbolo de diversidade sob à luz das teorias que tratam esse conceito academicamente.

Portanto, apresentar-se-á os princípios teórico-metodológicos inerentes à semiótica, nos quais reside o lugar desde onde se pensa a questão a ser desvelada. Igualmente, será discutida a categoria de análise acerca da diversidade com intuito de inserir a compreensão do símbolo da diversidade em uma discussão crítica e academicamente contextualizada.

\section{Pressuposto teórico-metodológico: semiótica}

A semiótica é a ciência da significação e se ocupa do estudo dos signos, em especial no que diz respeito aos seus sentidos e suas formas de produção de significados sustentadas em variadas linguagens. Vale destacar que a linguagem não se restringe à língua verbal, da qual se ocupam os estudos da linguística. De modo amplo, a semiótica repousa seu interesse sobre toda e qualquer linguagem (SANTAELLA, 2012b). 
A relação dos sujeitos com o mundo é possível por meio de uma constelação de linguagens, nas quais os signos desempenham papel de mediação (SANTAELLA, 2012b; 2004). Sendo assim, como seres simbólicos, as linguagens permeiam nossa existência:

\begin{abstract}
Não chegamos a tomar consciência que nosso estar no mundo, como indivíduos sociais que somos, é mediado por uma rede intrincada e plural de linguagem, isto é, que nos comunicamos também por meio da leitura e/ou produção de formas, volumes, massas, interações de forças, movimentos (SANTAELLA, 2012b, p.14)
\end{abstract}

A premissa que designa os signos como mediadores da realidade é sustentada nas discussões de Pierce (2005). Buscando falsear a ideia de intuição (presente imediato), teoricamente existente nos processos de cognição, Pierce (2005) demonstra que os pensamentos só existem e são cognoscíveis através de signos. Isso posto nas palavras conclusivas do autor, "todo pensamento, portanto, deve estar necessariamente em signos" (PIERCE, 2005, p.253). Desse modo, não haveria acesso direto aos objetos, mas sim essa relação ocorreria pela existência do pensamento composto pela mediação dos signos.

Em se tratando da forma como os signos suscitam efeito, para Pierce (apud SANTAELLA, 2012b) faz-se necessário o entendimento das características dos signos, uma vez que nem tudo que se apresenta à nossa mente se constitui no nível da representação, mas pode contemplar uma ação, uma experiência, ou mesmo uma qualidade de impressão. Desse modo, nessa relação cognitiva dos indivíduos com o mundo, haveria três elementos formais aos quais toda experiência estaria submetida, sendo estes: 1) Qualidade; 2) Relação/Reação; 3) Representação/Mediação. Esses níveis ocorrem correlacionados às categorias fenomenológicas de primeiridade, secundidade e terceiridade. As características das distintas dimensões dessa tríade ajudariam a compreender o processo que se instaura na construção da mediação interpretativa do mundo através de signos.

A primeira categoria diz respeito à acasionalidade e à espontaneidade com que os fenômenos se apresentam à consciência na sua condição de qualidade de ser e sentir. Nesses termos, a primeiridade refere-se ao presente imediato permeado por impressões incapturáveis. A segunda categoria está associada ao papel de referência factível que os signos desempenham em relação ao objeto, correspondendo à ação e reação dos fatos concretos. A terceira categoria se constitui a partir do signo enquanto mediação, sendo considerada triádica, na medida em que incorpora os processos imputados pelas categorias anteriores. É na terceiridade que se instaura o momento em que a inteligibilidade é possível por meio do signo enquanto lei (hábito) na sua capacidade de abstração e generalização, ou seja, quando o símbolo desempenha o papel efetivo de representação (SANTAELLA, 2012b). 
Respeitando as potencialidades e diante dos limites impostos a cada tipo de signo, compreende-se que os signos são capazes de representar um objeto, pelo menos em parte ou sob determinado aspecto. Ou seja, o signo tem a capacidade de estar no lugar do objeto dinâmico, mas sempre trazendo à luz determinada faceta. Assim, deve-se observar a que:

\begin{abstract}
O signo representa o objeto, porque, de algum modo, é o próprio objeto que determina essa representação, porém aquilo que está representado no signo não corresponde ao todo do objeto, mas apenas a uma parte ou aspecto dele. Sempre sobram outras partes ou aspectos que o signo não pode preencher completamente (SANTAELLA, 1995, p.49)
\end{abstract}

Essa mediação desempenhada pelo signo (representamen ou objeto imediato) ocorre entre o objeto fático (objeto dinâmico) e uma mente interpretante, sendo essa última entendida não enquanto um sujeito, e sim como o processo relacional que se dinamiza na mente do intérprete, através do qual outro signo se forma enquanto interpretação do primeiro (SANTAELLA, 2012b). As relações que se estabelecem na tríade entre objeto dinâmico, objeto imediato (signo) e a mente interpretante estão situadas em uma rede de interconexões infinitas chamada de Semiose:

O processo lógico de semiose, especialmente a relação entre objeto e interpretante sempre mediada pelo signo, a introdução do objeto imediato como uma outra inevitável mediação entre signo e objeto estabelece uma cadeia regressiva de signos do lado do objeto, assim como uma cadeia progressiva do de signos do lado do interpretante, de modo que os elos contínuos da linguagem se constituem em algo inquebrável (SANTAELLA, 1995, p.62).

Como é possível observar, o signo é composto por dois objetos: o dinâmico se constitui como o elemento na sua factualidade, ou seja, aquilo que o signo substitui; o imediato está associado à forma do signo, que não necessariamente precisa estar ligada à condição física do objeto dinâmico representado. Nesse processo de semiose, dois interpretantes são identificados: o imediato diz respeito à potencialidade que o signo está apto a produzir de acordo com sua natureza (qualidades, experiências, ação, encadeamento de pensamentos); o dinâmico remete ao que o signo efetivamente produz. Daí decorre a classificação dos signos, sempre respeitando uma relação triádica em dois sentidos: em relação às categorias de compreensão dos fenômenos (primeiridade, secundidade e terceiridade), que progressivamente encapsulam as potencialidades do ícone em estar no índice e de ambos em se encontrarem na composição do símbolo; no que determina a relação de mediação do signo entre o objeto imediato e o interpretante (SANTAELLA, 2012b). A sistematização abaixo permite compreender a questão:

\begin{tabular}{|l|l|l|l|}
\hline & \multicolumn{1}{|c|}{$\begin{array}{c}1^{\circ} \text { ) Signo em si mesmo (objeto } \\
\text { imediato) }\end{array}$} & \multicolumn{1}{|c|}{$2^{\circ}$ ) Signo com seu objeto dinâmico } & \multicolumn{1}{|c|}{$3^{\text {o }) \text { Signo com seu interpretante }}$} \\
\hline $1^{\text {o }}$ & Quali-signo & Ícone & Rema \\
\hline
\end{tabular}


RELACult - Revista Latino-Americana de Estudos em Cultura e Sociedade

\begin{tabular}{|l|l|l|l|}
\hline $2^{\circ}$ & Sin-signo & Índice & Discente \\
\hline $3^{\circ}$ & Legi-signo & símbolo & Argumento \\
\hline
\end{tabular}

Quandro 1 - Fonte: Santaella (2012b), adaptado pela autora

Diante das relações acima, o quali-signo (incônico-remático) se refere a uma mera qualidade, sem representar um objeto dinâmico em si, mas sim uma sensação ou sentimento, indicando uma hipótese. O sin-signo (indicial-discente) é passível de indicar um objeto dinâmico existente em concreto, ou seja, há uma conexão de fato entre ambos objetos imediato e dinâmico. No campo dos legi-signos (argumental simbólico), o signo não representa o objeto dinâmico no que tange as suas qualidades, tampouco por manter uma relação factual, mas tem capacidade de representação por meio de uma convenção que permite que ao símbolo representar um objeto no seu conjunto geral (SANTAELLA, 2012b).

Contudo, Santaella (1992) chama atenção para a relatividade da classificação dos signos, atentando para a hibridez desses no processo de semiose. A terceiridade, apresentada na tabela acima, seria caracterizada pelo signos genuínos, uma vez que o símbolo repousaria em uma relação triádica genuína e traria, fundamentalmente, dentro de si ícones e índices. Por outro lado, o índice e o ícone constituir-se-iam enquanto signos degenerados ou quase-signos diante da falta da tríade genuína (SANTAELLA, 1992).

Porém, as categorias de apreensão dos fenômenos existiram dentro de todos os signos. Por exemplo, os ícones podem ser divididos em ícone puro, ícone atual e hipo-ícone, mas a relação triádica que este último contempla não se caracterizaria da mesma forma que a tríade genuína presente na dimensão dos símbolos. Nesse último estágio do hipo-ícone, Santaella explica:

O signo icônico, por sua vez, já mais sistematizado por Pierce, diz respeito a algo que já se apresenta como signo, representando alguma coisa, e, como tal, intrinsecamente triádico, embora se trate de uma tríade não genuína, visto que regida por relações de comparação e cuja referência ao objeto se dá por semelhança. Sendo triádico, o signo incônico ou hipo-ícone terá três faces ou graus correspondentes: 1) à imagem; 2) ao diagrama; e 3) à metáfora (SANTAELLA, 1995, p.145).

Na presente pesquisa serão analisadas imagens. Todavia, Santaella (1995) adverte para o fato de que as características das imagens não estão restritas à dimensão dos hipo-ícones. Essa questão será retomada na análise. Por fim, ainda que a semiótica não seja exclusiva às proposições de Pierce, os breves princípios conceituais apresentados constituem o norte teóricometodológicos para apresentar e desenvolver as questões previamente levantadas.

\section{Categoria de análise dos resultados: diversidade cultural}


Através das proposições apresentadas por Renato Ortiz (1999) e Gustavo Lins Ribeiro (2008), constata-se que a concepção de diversidade se modifica, seja por meio do desenvolvimento histórico de conceitos, como o de cultura por exemplo (RIBEIRO, 2008), ou mesmo a partir das diferentes abordagens e lugares teóricos de problematização em que se encontram os objetos de cada ciência. Conforme observam esses pesquisadores, a diversidade no que tange o aspecto cultural tem permeado os estudos do campo da Antropologia, Sociologia e da História. A história desvelou a existência de diversos povos, com suas peculiaridades culturais e políticas (ORTIZ, 1999). Nesse contexto, a diversidade estaria atrelada à variedade de civilizações existentes ao longo do tempo. No final do século XIX a Antropologia emergiu diante da percepção da diferença, inerente ao sentimento exótico que os povos tradicionais despertaram nos primeiros pesquisadores (LAPLANTINE, 2003; ORTIZ, 1999). Nas palavras de Laplantine (2003) é possível vislumbrar a diversidade no cerne da problemática antropológica desde o trabalho dos primeiros etnólogos:

esses homens do século passado colocavam o problema maior da antropologia: explicar a universalidade e a diversidade das técnicas, das instituições, dos comportamentos e das crenças, comparar as práticas sociais de populações infinitamente distantes uma das outras tanto no espaço como no tempo (LAPLANTINE, 2003, p.54).

Na contemporaneidade, as diferenças estão sob a luz do interesse da antropologia e essas são estudadas sob o exercício da alteridade e da relativização (ORTIZ, 1999; PEIRANO 2003). Assim, a antropologia tem iluminado a diversidade cultural ao descrever e compreender as práticas simbólicas de diferentes grupos e povos (ORTIZ, 1999).

Pensando a globalização e a constituição do Estado fundamentada na ideia de nação, que deve conceber cada país como uma unidade cultural própria ${ }^{2}$, Ortiz (1999) defende que a diversidade passa a significar o conjunto de entrelaçamentos de culturas nacionais diversificadas. Refletindo sobre os aspectos globalizantes que tenderiam a homogeneizar a diversidade, o autor pondera que, ainda que a modernidade atravesse as nações, essas encontram diferentes maneiras de realizá-la.

Esses exemplos demonstram como variadas problemáticas teóricas apresentam formas próprias de conceber a diversidade. Para Ortiz (1999), a diversidade se aplica em dois diferentes contextos: as variadas civilizações e formações sociais; a diferenciação presente na modernidade, mobilizada pelos movimentos sociais. Dois exemplos materializam esse último quesito: o autor chama atenção para a necessidade de qualificar e descrever as diferenças, pois

\footnotetext{
2 O que não se resume em uma homogeneidade pacífica. O autor assume que há contradições e disputas de sentido envolvidas.
} 
no universo de povos indígenas, por exemplo, haveria uma pluralidade cultural que caracterizaria cada tribo, sendo insuficiente empregar a figura do indígena no singular para representá-los no campo da diversidade; ou ainda, integrar todos os movimentos sociais no conjunto das minorias seria uma equívoco homogeneizador. Em uma segunda perspectiva em busca da compreensão das características da diversidade, no que tange a qualificação das formas como a diversidade se expressa, Ribeiro (2008) traz para a discussão três panoramas: 1) particularismos locais; 2) particularismos trans-locais; 3) particularismos cosmopolitas.

No primeiro caso, são apresentadas especificidades que estão limitadas social e espacialmente, fazendo com que a diversidade se constitua pelo contraste entre grupos. As práticas sociais oriundas dessa perspectiva, por vezes, tenderiam à segregação social em decorrência de visões extremistas que designariam a fronteira nós/eles. Canclini (2004) critica esse multiculturalismo, que por um lado deu visibilidade à diversidade cultural, porém foi também capaz de gerar um etnocentrismo que impossibilitou pensar os entrecruzamentos entre culturas. Em decorrência, o autor utiliza em contraste os conceitos de multiculturalidade e multiculturalismo:

La multiculturalidad, o sea la abundancia de opciones simbólicas, propicia enriquecimientos y fusiones, innovaciones estilísticas tomando prestado de muchas partes. El multiculturalismo, entendido como programa que prescribe cuotas de representatividad en museos, universidades y parlamentos, como exaltación indiferenciada de los aciertos y penurias de quienes comparten la misma etnia o el mismo género, arrincona en lo local sin problematizar su inserción en unidades sociales complejas de gran escala (CANCLINI, 2004, p.22).

Na segunda expressão cunhada por Ribeiro (2008), o intercâmbio cultural marca as relações estabelecidas pela diversidade, a qual é vivenciada sem estranheza e enquanto um elemento fundante dos sujeitos em situação de diáspora, por exemplo. Dessa forma, a diversidade admite os processos de hibridização.

Diante desses dois primeiros contextos, advém invocar as diferenças entre multiculturalidade e interculturalidade. A multiculturalidade, tendo como consequência as políticas relacionadas ao multiculturalismo, reforçaria a segregação, pois diante da assunção da diversidade decorreriam políticas relativistas de respeito que levariam à separação e não à compreensão da relação entre as culturas. Por outro viés, o conceito de interculturalidade pressupõe abordar as culturas nas suas relações de intercâmbio e poder (CANCLINI, 2004). De forma prática,

Ambos términos implican dos modos de producción de lo social: multiculturalidad supone aceptación de lo heterogéneo; interculturalidad implica que los diferentes son lo que son en relaciones de negociación, conflicto y préstamos recíprocos (CANCLINI, 2004, p.15). 
A perspectiva da interculturalidade concentra-se em estudos Anglo-saxões (embasados na comunicação intercultural), franceses (focados na integração e adaptação dos imigrantes) e Latino-americanos (a partir das relações interétnicas). Colocar-se na dimensão do intercultural pressupõe centrar a problematização sobre as misturas e conflitos que permeiam a vinculação entre os grupos, os quais se materializam nos distintos modos de apropriação, consumo e interpretação de bens materiais e simbólicos (CANCLINI, 2004).

Por último, o terceiro termo empregado por Ribeiro (2008), chamado de Cosmopolitismo, engloba sujeitos transnacionais que concebem as dimensões política e cultural para além das suas fronteiras territoriais, vislumbrando uma comunidade planetária. Nesse contexto, o indivíduo deve ir além das suas condições etnocêntricas para assumir a diferença de modo positivo diante do desafio de construir relações globais pacíficas e igualitárias.

Esses três panoramas conceituais permitem pensar as qualidades e consequências dos modos como as expressões sobre a diversidade se concretizam e que essa noção não é algo naturalizado, mas politicamente e historicamente construída. Ainda, no que toca a qualificação da diversidade, outro contraponto trazido por Ortiz (1999) diz respeito ao fato de que a diversidade, quanto vista sob a perspectiva da diferença, deve despertar o olhar para as suas condições históricas e sociais de produção: "afirmar o sentido histórico da diversidade cultural é submergi-la na materialidade dos interesses e dos conflitos sociais" (ORTIZ, 1999, p.83). Portanto, a diversidade deve ser historicizada e politizada, uma vez que sob ela subjaz categorias culturais que não são equivalentes (ORTIZ, 2007). Assim, para o pesquisador, apenas a relativização, sem a compreensão do que produz a diferença no seu percurso histórico e social, seria insuficiente para abarcar de forma crítica a diversidade. Desse modo, não se compreenderia as desigualdades resultantes das relações de poder sob as quais se forja a diversidade.

Por fim, Ortiz (2007) pontua que o universal e o particular são opostos, estando a diferença atrelada ao particular de modo incompatível com a universalização. Porém, esses dois movimentos se entrelaçariam no cenário global. Esse posicionamento do autor ocorre ao analisar discursos e documentos de organizações internacionais. As afirmações que defendem que 'a diversidade dos povos deve ser preservada' ou que 'as culturas são um patrimônio da humanidade' inserem, em um contexto global, a diversidade enquanto um valor universal. $\mathrm{O}$ interstício entre universal e particular apresenta-se, também, no fato de que as diferenças são elencadas e justificadas a partir de argumento universalistas (democracia, igualdade, direitos humanos e cidadania) que ressignificam a forma como as diferenças são entendidas. Nesse mesmo movimento, sobre esses sentidos universais, Gustavo Lins Ribeiro (2008) discute como 
o conceito de diversidade se torna universal entre os de "desenvolvimento", "direitos humanos" e "valores universais excepcionais".

A diversidade enquanto discurso está situada em um campo de disputas de sentidos, onde os sujeitos podem utilizar essa representação para reforçar ou contrariar hegemonias (RIBEIRO, 2008). Esse campo é tensionado por visões contraditórias e, além dos Estadosnação e das organizações de comunicação, nele estão inseridos os agentes e as agências de governança global, que tendem a manejar a pluralidade de demandas e visões oriundas de diferentes níveis multiescalares traçados pela globalização. (RIBEIRO, 2008). Esse cenário de cosmopolíticas envolve a transformação da diversidade cultural em uma ideologia central que as agências de governança global tentam universalizar através de políticas de alcance mundial. A Declaração Universal sobre Diversidade Cultural da UNESCO (2001) representa o empreendimento descrito (RIBEIRO, 2008). Essa diretriz internacional implementa a produção de uma cosmopolítica fundamentada na diversidade cultural.

Composta por 12 artigos, a declaração (2001) concebe a diversidade cultural como uma característica inerente ao gênero humano e passível de ser patrimônio da humanidade. Ainda, no documento, a diversidade cultural deve ser pensada a partir de um diálogo harmonioso e sustentada no ideal de direitos humanos, o qual baseia-se no respeito entre as culturas, no direito ao exercício da cultura e ao acesso aos bens culturais fomentados pelos políticas estatais. Contudo, Ribeiro (2011) demonstra que a particularidade da diversidade cultural coloca em questionamento o próprio ideal universal de direitos humanos, pois esse passa a ser relativizado pelos diferentes contextos e qualidades das diferenças culturais que desse ideal se apropriam. Por outro lado, Ortiz (1999) argumenta que é justamente o fato de a diversidade cultural transformar-se em valor universal, que os indígenas passaram a ter direito à terra desde a sua perspectiva particular, por exemplo.

Os meios de comunicação também desempenham papel importante nesse contexto de universalização de valores, aqui em específico o da diversidade:

As tecnologias de comunicação tornaram-se um foco de explorações sobre cultura global, assim como sobre a emergência de novas e flexíveis identidades, interações eletrônicas e espaços públicos, hibridismo cultural e comunidades políticas cosmopolitas (RIBEIRO, 2011, p.211).

É diante das pautas apresentadas que se busca compreender sob qual paradigma e como se concretiza o símbolo da diversidade na comunicação turística do Carnaval de Recife (2019).

\section{Objeto, método e análise}


A análise está restrita à comunicação turística implementada no Carnaval de Recife no ano de 2019. A temática do evento versava sobre a diversidade cultural sob o slogan "O Carnaval de Todo Mundo", o qual também foi atribuído ao espetáculo de abertura, realizado no principal palco do Marco Zero. De forma discursiva, a diversidade é evidenciada na apresentação da edição de 2019, disponível no aplicativo mobile desenvolvido pela prefeitura de Recife (organizadora do carnaval):

Capital do Nordeste, o Recife se destaca no ciclo carnavalesco pela autenticidade e pluralidade de suas manifestações culturais, que passeiam pelo cenário do frevo e seus clubes de frevo e de bonecos, blocos líricos, tribos de índios, caboclinhos, escolas de samba, afoxés, ursos, bois de carnaval e maracatus de baque solto e virado. Uma festa onde o folião é o rei e a rua é do povo, uma confraternização na qual as mais diversas sonoridades são vivenciadas em todas as regiões da cidade ${ }^{3}$.

No discurso acima fica evidente a inter-relação entre o carnaval e a imagem do destino Recife, apresentando a variedade (pluralidade) das manifestações culturais como uma diferenciação (destaque) que caracteriza seu carnaval frente aos demais (ciclo carnavalesco). Para exaltar a diversidade descrita, a Gerência Geral de Arquitetura e Engenharia da Fundação de Cultura Cidade do Recife, em conjunto com a Diretoria Executiva de Comunicação Institucional, criaram 40 ilustrações de personagens baseados em foliões do carnaval. Esses personagens foram utilizados nos recursos comunicacionais, desde a cenografia urbana, passando pelos materiais impressos, cartilhas, mídias e aplicativos digitais.

Com intuito de analisar o material produzido nesse contexto, o método utilizado tem como base a proposta aplicada em uma pesquisa desenvolvida por Baldissera et al. (2010b), a qual parte de princípios semióticos. O procedimento metodológico se divide em quatro etapas: I) seleção e identificação; II) análise pré-iconográfica (descrição); III) análise iconográfica (identificação das temáticas ou classificação); IV) análise interpretativa (compreensão do signo representado a partir de suas cores, formas, cortes, sujeitos e objetos).

A primeira etapa de seleção e coleta foi feita a partir dos materiais digitais, tendo em vista a facilidade de acesso. Assim, foram analisados os 30 avatares ${ }^{4}$ criados com base nas 40 ilustrações citadas anteriormente. Ainda, nesse primeiro estágio, buscou-se identificar as características das imagens a partir dos preceitos semióticos. Mesmo que Pierce tenha identificado três tipos de hipo-ícones (imagem, diagrama e metáfora), Santaella (1995) chama

\footnotetext{
${ }^{3}$ Grifos da autora.

${ }^{4}$ Os avatares são imagens elaboradas para serem utilizadas nas páginas pessoais das redes sociais de cada usuário. Dos 40 personagens criados para as ações de comunicação desenvolvidas no Carnaval de Recife de 2019, apenas 30 foram disponibilizados como avatares.
} 
atenção para o fato de que ícone e imagem não são equivalentes em todos os casos e, nesse sentido, as imagens não se restringem à condição de hipo-ícone.

$\mathrm{Na}$ perspectiva das classificações propostas por Santaella (2012a), haveria três paradigmas distintos: o pré-fotográfico, cujas características estão centradas no aspecto artesanal do artista, caracterizando a imagem como inacabada; o fotográfico, no qual a máquina é um extensão do olhar, sendo a imagem fruto de cortes que fixam movimento, espaço e tempo; o pós-fotográfico, resultante da racionalidade matemática do computador, que caracteriza a imagem por sua virtualidade, sendo inexistente a presença do real no processo de produção. No que tange a natureza das imagens e sua relação com o mundo, a pré-imagem figura o visível, a imagem fotográfica registra o visível, e a pós-imagem visualiza o modelizável (SANTELLA, 2012a).

De acordo com a pesquisadora (2012a), haveria uma interdependência para além das características de cada paradigma imagético, através da qual os modelos se fundem e trazem dentro de si elementos do paradigma antecessor. A partir desse paradigma, pode-se dizer que a elaboração dos personagens aqui analisados resultou de um processo híbrido, na medida em que imagens fotográficas foram utilizadas como suporte para criação das ilustrações computadorizadas (pós-fotográficas).
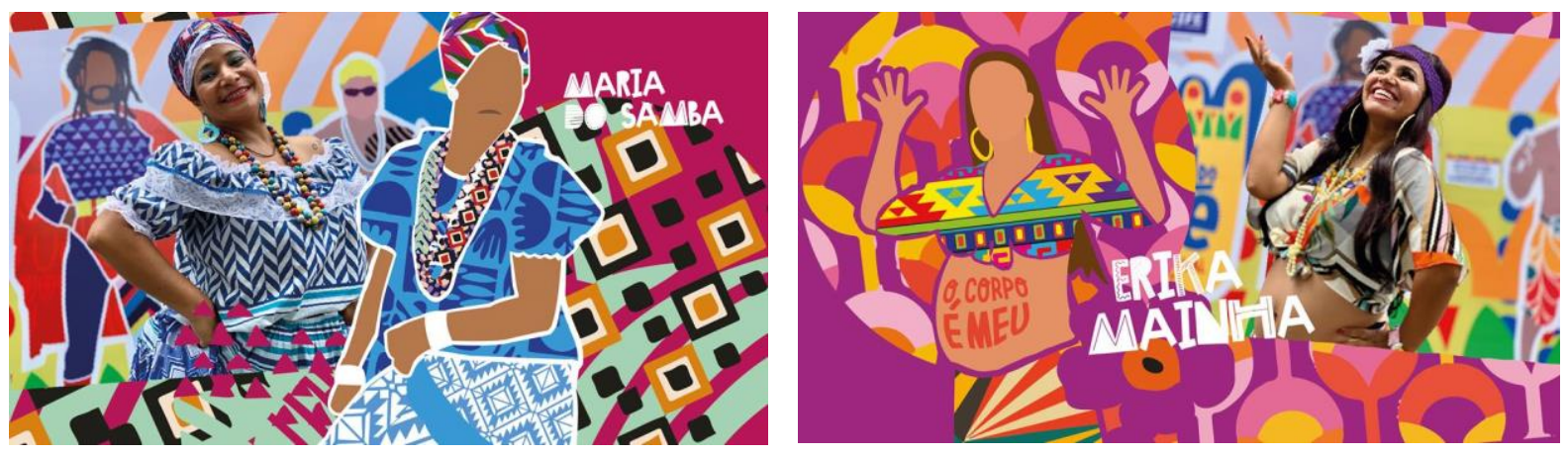

Fonte: Prefeitura de Recife

No presente estudo, as imagens resultantes para representar a diversidade configuram-se como legi-signos ${ }^{5}$ marcados pelo cálculo computacional, porém baseados em fotografias arraigadas no aspecto indicial ${ }^{6}$, ou seja na relação físico-existencial proeminente. Contudo, os signos gerados enquanto imagens pós-fotográficas também tratam de categorias gerais dos objetos representados, as quais são indicadas nas palavras samba e mainha, as fazendo operar enquanto símbolos. No campo semiótico, o símbolo

não representa seu objeto em virtude do caráter de sua qualidade (hipoícone), nem por manter em relação ao seu objeto uma conexão de fato (índice), mas extrai seu poder de representação porque é portador de uma lei que, por convenção, ou pacto coletivo,

\footnotetext{
${ }^{5}$ Categoria que diz respeito a descrição do signo nele mesmo: quali-signo; sin-signo; legi-signo;

6 Categoria associada à descrição da relação do objeto imediato com o objeto dinâmico: ícone; índice; símbolo.
} 
determina que aquele signo represente seu objeto [...] o símbolo não é uma coisa singular, mas um tipo geral (SANTAELLA, 2012b, p.104-105)

A condição indicial singular da imagem está materializada nos nomes dos sujeitos retratados, representados nas palavras Erika e Maria, que associam o signo ao referente factual. A relação indicial estabelecida entre os objetos dinâmico e imediato da imagem fotográfica não desfaz a natureza de legi-signo das imagens pós-fotográficas, isso porque "todo símbolo é legisigno, mas nem todo legi-signo é simbólico. Ele também pode ser um legi-signo icônico ou indicial" (SANTAELLA, 1995, p.175). De forma complementar, as palavras Erika e Maria figuram os aspectos indiciais da imagem criada enquanto computação gráfica, já as convenções mainha e samba indicam a dimensão simbólica que esse legi-signo pode carregar na sua condição de lei.

À título de análise, vale apontar que o fato de serem indiciais e terem uma relação com sujeitos que representam aspectos da cultura local, isso não significa que o conjunto de signos gerados não possa remeter a um sentido globalizado de diversidade tomado enquanto valor universal, conforme discutido no campo teórico.

O segundo momento diz respeito à ordenação e descrição das figuras em uma planilha de modo a facilitar a análise e classificação. O método de descrição empregado se assemelha aos empregados por Bardin (2011) na análise de conteúdo. Na terceira fase, que contava com a identificação das temáticas, pode-se verificar 10 figuras claramente associadas a traços culturais, 2 relacionadas à questão de gênero e 1 atrelada à problemática da acessibilidade. Os demais 17 avatares retratavam fantasias de carnaval, tais como super-heróis, frutas, animais, profissionais, criaturas imaginárias (diaba e unicórnio), etc.

$\mathrm{Na}$ quarta etapa foi possível observar que a diversidade é trazida à tona sob diferentes aspectos/símbolos ${ }^{7}$. A diversidade étnico-racial é composta por um conjunto de signos icônicos e indiciais que atravessa todas as ilustrações e é expresso pela cor da pele, pelo formato dos cabelos e pelos traços ou elementos culturais. Os fenótipos faciais estão apagados nas imagens. Seis cores foram utilizadas para tonalizar a cor da pele: Marrom-Amarelo (2); Marrom (5); Marrom-escuro (8); Bege (2); Rosa (8); Laranja (4). Os cabelos são igualmente bastante diversos: Cabelo Afro (2); Cabelo Afro Colorido (1); Cabelo Crespo (1); Cabelo Liso Colorido (1); Cabelo Liso Castanho (3); Cabelo Liso Preto (2); Cabelo Loiro (2); Cabelo Ruivo (1). Os elementos culturais indiciais identificados foram: Turbantes (2); Acessórios (5); Instrumentos musicais (1). A diversidade cultural também é remetida pela conjunção simbólica das

\footnotetext{
${ }^{7} \mathrm{Nem}$ todas as imagens apresentam os rostos, pois muitos estão camuflados por fantasias. Nesse sentido os número não compreendem a totalidade dos 30 avatares.
} 
manifestações culturais do Estado de Pernambuco representadas no material, tais como o Maracatu Nação (3), o Maracatu Rural (1), o Samba (2) e o Frevo (2), as quais podem ser identificadas através dos traços das roupas, gestos corporais associado à linguagem da dança, acessórios e instrumentos. Figuras da cultura urbana também estão presentes (surfista e o rapper). Novamente, é importante ressaltar que a dimensão simbólica cultural é passível de ser interpretada por meio do intrínseco conjunto de roupas, de objetos, de acessórios e da linguagem corporal. A diversidade de gênero é problematizada pelas Drag Queens. A diversidade em termos de acessibilidade é trazida à tona na figura de uma grávida.

Com intuito de concretizar o alcance analítico do primeiro e do segundo objetivos específicos levantados na proposta de pesquisa, a análise descritiva acima pode ser sistematizada da seguinte forma:
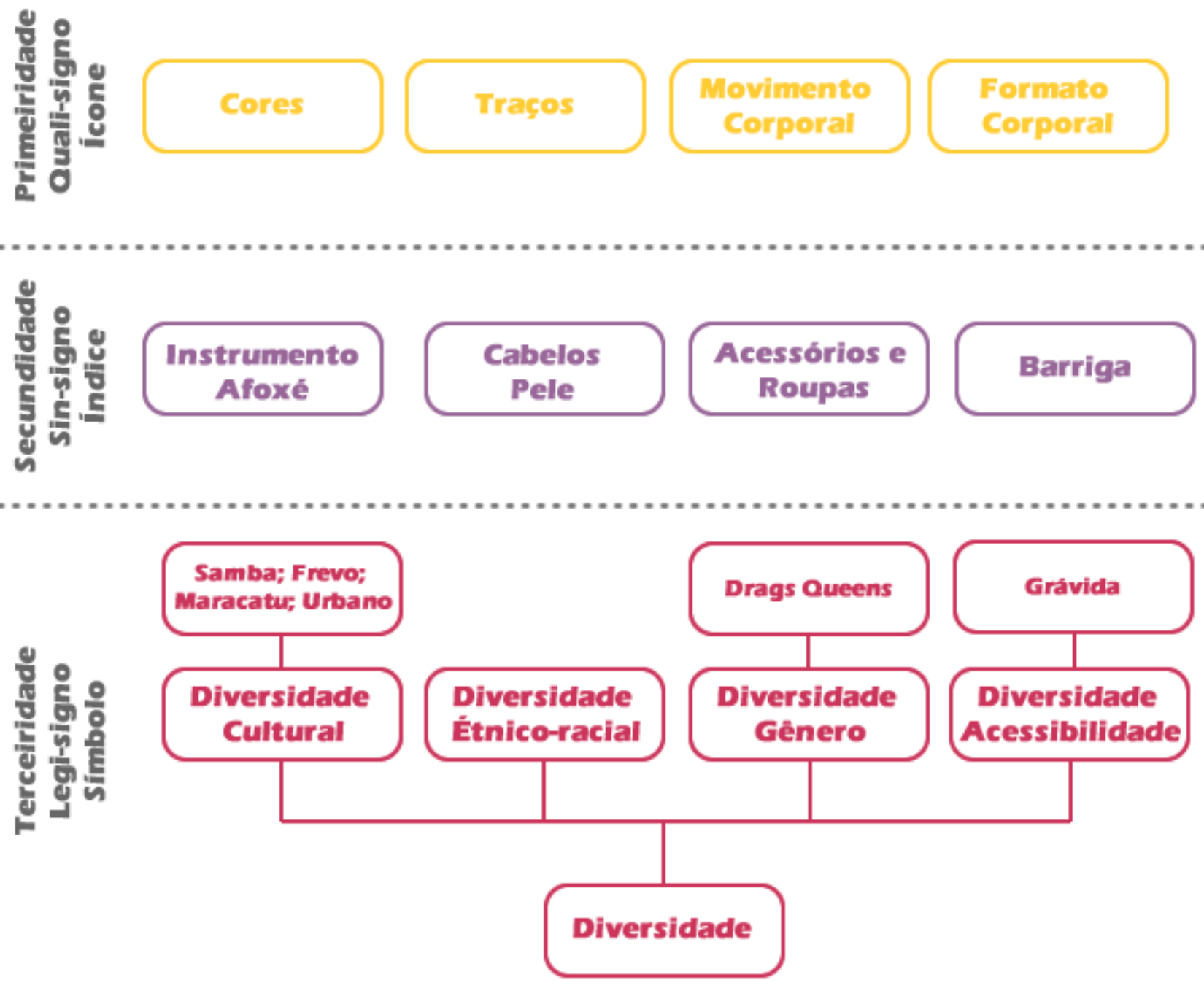

Esquema 1

Fonte: Imagem elaborada pela autora 
Os ícones e índices descritos estão presentes na conformação dos símbolos apresentados, uma vez que, conceitualmente, os signos são híbridos e, sendo assim, símbolos podem trazer características icônicas e indiciais (SANTAELLA, 2012b). Se na primeiridade apresentam-se os quali-signos (icônico-remático), que despertam sentimentos e impressões imediatas da relação do indivíduo com o mundo ou objeto, na secundidade esse processo irrompe para a conformação de um sin-signo (indicial-discente), que transgride o limite da hipótese levantada no nível da primeiridade para chegar a um pensamento constatativo onde o índice tem uma relação de fato com seu objeto, a partir daí conformam-se os legi-signos (símbolo argumentativo) capazes de representar uma convenção e uma generalidade. O ícone e o índice seriam quase-signos, haja vista que o fundamento do signo leva em conta o entrelaçamento dos três níveis expostos anteriormente (SANTAELLA, 2012b, 1995).

\footnotetext{
Para funcionar como signo, algo tem de estar materializado numa experiência singular, que tem lugar no mundo (real ou fictício) e reage em relação a outros existentes de seu universo. [...] Essas três gradações, baseadas nas categorias de qualidade (primeiridade), reação (secundidade) e mediação (terceiridade), são onipresentes (SANTAELLA, 1992, p.77).
}

De forma prática, em alguns casos, é possível perceber uma unidade formada por traços e cores (hipo-ícones), além de elementos de figurino ${ }^{8}$ (índice), que associam os personagens a um mesmo subconjunto de símbolos que irão remeter ao símbolo da diversidade, conforme pode ser observado abaixo:

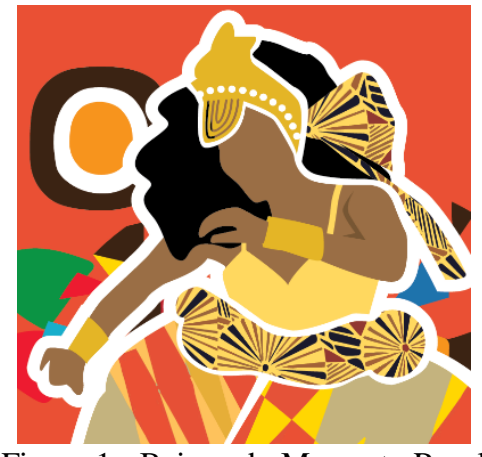

Figura 1 - Baiana do Maracatu Rural

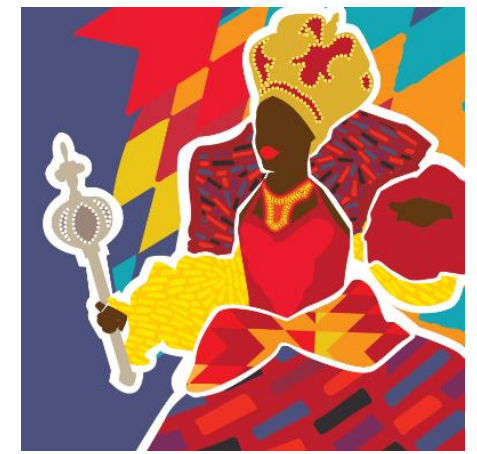

Figura 2 - Rainha do Maracatu Rural

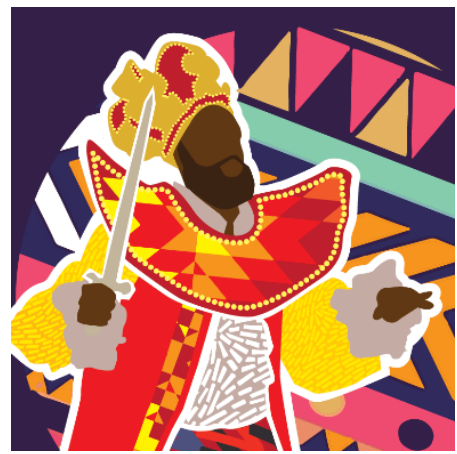

Figura 3 - Rei do Maracatu Rural

\footnotetext{
${ }^{8}$ Tais como roupas, acessórios e maquiagens.
} 


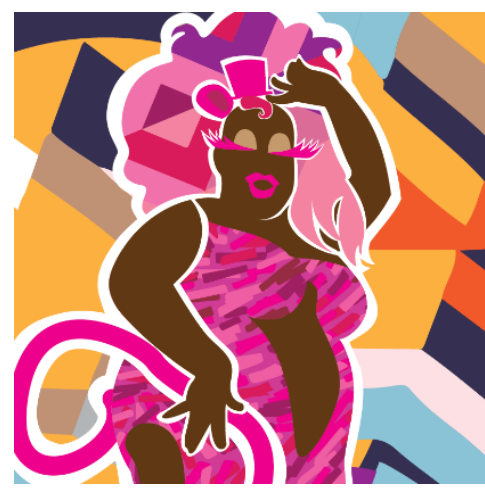

Figura 4 - Drag Queens 1

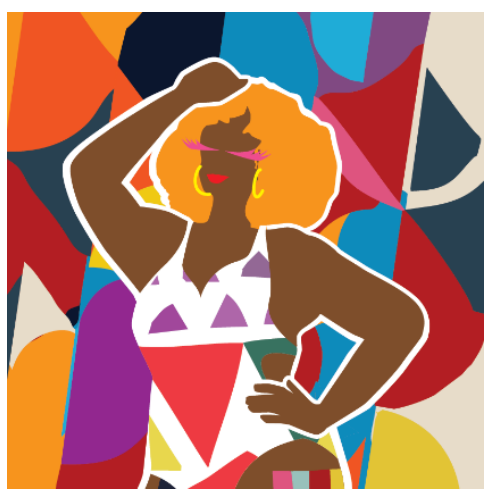

Figura 5 - Drag Queens 2

Fonte: Prefeitura de Recife

Como argumenta Santaella (1995), as imagens podem servir de contexto para imagens e podem ser interpretadas em conjunto. Nos exemplos acima, os hipo-ícones classificados como imagens por Pierce estão presentes e tratam das Primeiras Primeiridades, ou seja baseiam-se nas singularidades em termos de qualidade relacionada à forma, cor, textura, volume, movimento. Nesse conjunto de traços semelhantes, as imagens isoladas se unem na sua similaridade enquanto quali-signos para constituir os índices e, por conseguinte, os símbolos (Maracatu, por exemplo). Ainda que as imagens sejam caracterizadas individualmente como legi-signos indiciais, a conjunção do seu mosaico forma o legi-signo, simbólico, argumental da diversidade tendo em vista sua potencialidade de generalização, lei, hábito ou silogismo.

As associações apresentadas entre os símbolos $^{9}$ remetem à concepção de que o processo de semiose pode ser infinito, uma vez que os signos remetem constantemente a outros signos e assim por diante (SANTAELLA, 2012b). Essa cadeia de relações estabelecidas é indicada por Pierce ao tratar da cognição e sua possibilidade de existência somente através de pensamentos em signos:

Além do mais, todas as faculdades cognitivas que conhecemos são relativas e, por conseguinte, seus produtos são relações. Mas a cognição de uma relação é determinada por cognições prévias. Portanto, não se pode conhecer cognição alguma que não seja determinada por uma cognição anterior. Portanto, ela não existe primeiro porque é absolutamente incognoscível e, segundo, porque uma cognição só existe na medida em que é conhecida (PIERCE, 2005, p.255).

Por fim, no que tange ao terceiro objetivo específico proposto, a síntese da quarta etapa metodológica permitiu compreender os núcleos de sentidos que compõem o símbolo da diversidade, concretizado no conjunto de 30 avatares analisados. Esse cerne é composto por conceitos universais que recortam a realidade a partir de seus aspectos particulares, sem a

\footnotetext{
${ }^{9}$ Por exemplo, do símbolo do Maracatu, que remete ao símbolo de diversidade cultural, que compõe o símbolo de diversidade.
} 
intenção de problematizá-los, mas sim de trazê-los enquanto composição das representações de variedade, de pluralidade ou de multiplicidade que conforma o símbolo da diversidade. A característica multicolorida intensifica a diversidade enquanto variedade. As culturas representadas demonstram a variedade da diversidade cultural. O próprio símbolo de diversidade é acionado por um subconjunto de símbolos (diversidade cultural, diversidade étnico-racial, diversidade de gênero e diversidade em termos de acessibilidade), atribuindo-lhe caráter polissêmico. Por ser um símbolo abstrato, o conceito de diversidade se materializa através do acionamento de ícones e índices, que ligam a universalidade do conceito de diversidade ao contexto factual no qual ela se aplica. Esse modo de acionar o conceito de diversidade deverá ser analisado em outros estudos de caso.

Nesse contexto, a diversidade é materializada a partir do princípio da multiculturalidade, que aponta para a existência da variedade cultural, mas que não problematiza a construção histórica-social da produção da diferença. A perspectiva concretizada através das imagens já era anunciada no material discursivo verbal apresentado no aplicativo do carnaval, conforme exposto anteriormente.

\section{Considerações finais}

Conclui-se que os objetivos específicos foram desenvolvidos, permitindo a compreensão de como opera o jogo de signos na semiose da diversidade, materializada através dos avatares utilizados na comunicação turística do Carnaval de Recife de 2019. Foi possível visualizar a forma prática como ocorre a operação das distintas potencialidades presentes na conformação das três principais categorias de signo, bem como operam seus entrelaçamentos na constituição do símbolo da diversidade.

Considerando as implicações práticas ocasionadas pelas características do símbolo desvelado, os sentidos aí produzidos devem ser pensados de modo mais aprofundado e em articulação com as questões problematizadas pela discussão teórica sobre a diversidade. Portanto, torna-se necessário questionar-se sobre os limites da representação no campo da linguagem visual para tratar de aspectos políticos inerentes às concepções de diversidade. Devese indagar sobre quais formas sensíveis da vida estão passíveis de serem representadas por imagens, isoladas ou em rede, e em quanto essa linguagem visual é potência para traduzir símbolos mobilizados pela linguagem verbal ou, em que medida essas imagens tem seus traços atravessado por outras linguagens. Ainda, resta compreender qual nível de problematização cada linguagem é capaz de propor. 
No que toca a tentativa de construção da diferenciação do carnaval de Recife por meio da semiose da diversidade, ressalta-se a importância de se refletir sobre os aspectos universais que esse conceito carrega, fazendo com que sua premissa possa ser aplicada em qualquer outro contexto, sem efetivamente gerar diferenciação, na medida em que trabalha sobre a premissa da pluralidade, inerente às sociedades contemporâneas.

\section{Referências}

BALDISSERA, R.; GONÇALVES, S.; LIEDKE, E. O Imaginário de Porto Alegre por seus cartões-postais. In: Em Questão, Porto Alegre, v. 16, n. especial, p.79 - 94, out. 2010b. P.7994.

BARDIN, L. Análise de Conteúdo. São Paulo: edições 70, 2011.

CANCLINI, N. G. Diferentes, Desiguales y Desconectados: Mapa de la Interculturalidad. Barcelona: Editora Gedisa, 2004.

CUNHA, N. Visite Uruguay: del balneário al país turístico. Ediciones de la banda oriental: Montevideo, 2012.

GASTAL, S. Turismo, imagens e imaginários. São Paulo: Aleph, 2005.

LAPLANTINE, F. Aprender Antropologia. São Paulo: Brasiliense, 2003.

LIPOVETSKY, G.; SERROY, J. A Cultura-mundo: resposta a uma sociedade desorientada. São Paulo: Companhia das Letras, 2011.

ORTIZ, R. Anotações sobre o universal e a diversidade. Revista Brasileira de Educação v. 12 n. 34 jan./abr. 2007. p.7-16

ORTIZ, R. Diversidade cultural e cosmopolitismo. Revista Lua Nova, no.47, São Paulo, Agosto. 1999. p.73-89

PEIRANO, M. A teoria vivida e outros ensaios de antropologia. Rio de Janeiro: Jorge Zahar, 2006.

PIERCE, C. Semiótica. São Paulo: Perspectiva, 2005.

RIBEIRO, G.L. Diversidade cultural enquanto discurso global. In: Desigualdade \& Diversidade: Revista de Ciências Sociais da Puc-Rio, Rio de Janeiro, n. 2, p. 199-233, jan./

jun. 2008.

SANTAELLA, L.; WORTH, W. Imagem, cognição, semiótica, mídia. São Paulo: Iluminuras, $2012 \mathrm{a}$

SANTAELLA, L. O que é Semiótica. São Paulo: Brasiliense, 2012b 
SANTAELLA, L. Semiótica Aplicada. São Paulo: Thomson Learning. 2007

SANTAELLA, L. Comunicação e Semiótica. São Paulo, SP : Hacker, 2004.

SANTAELLA, L. A Teoria Geral dos Signos: Semiose e autogeneração. São Paulo: Editora Ática 1995

SANTAELLA, L. A Assinatura das coisas: Pierce e a Literatura. Rio de Janeiro: Imago Ed., 1992.

UNESCO. Declaração Universal sobre Diversidade Cultural, 2001. 